\title{
The effects of LED light sources on the parameters defining the quality of electricity
}

\author{
Andrzej Lange ${ }^{1, *}$, Marian Pasko ${ }^{2}$ \\ ${ }^{1}$ University of Warmia and Mazury in Olsztyn, Department of Electrical and Power Engineering, Electronics and Automation, EDP \\ Sciences, Editorial Department, 10-736 Olsztyn, ul. Oczapowskiego 11, Poland \\ ${ }^{2}$ Silesian University of Technology, Institute of Electrical Engineering and Computer Science, 44-100 Gliwice, Akademicka 2A, Poland
}

\begin{abstract}
The article presents the regulations and standards relating to the quality of electricity, with special emphasis on higher current and voltage harmonics in high-voltage, medium-voltage and low-voltage power grids and the power factor (PF). The parameters defining the quality of electricity consumed by modern LED bulbs for lighting homes, industrial premises such as offices and production halls, as well as roads and yards were measured and analyzed. The current waveforms for LED lights were presented upon connection to the power grid.
\end{abstract}

\section{Preface}

Light sources based on the LED technology are increasingly used to light homes, industrial premises and outdoor sites such as roads. LED bulbs are gradually replacing less economical incandescent bulbs and energy-saving gas-discharge lights. Gas-discharge bulbs are more energy efficient, but they exert a negative effect on the power grid by causing overvoltage on ignition, generating higher current harmonics to the power grid, and absorbing passive inductive power from the grid (when inductive ignition systems are used). LED bulbs are characterized by high luminous efficacy and long life.

\section{Standards and regulations on electricity quality}

Selected provisions of the European Union directives, Polish regulations and standards are presented in the References section in points [1] to [12]. These regulations define the minimum requirements for electricity quality and supply voltage (higher harmonic frequencies) and the power factor $\cos \varphi$.

\section{Structure of LED light sources}

LED bulbs have the following components: a rectifier circuit, a capacitor for smoothing the voltage supplied by the rectifier, a current-voltage regulator, and lightemitting diodes connected in series and in parallel. The complexity of the rectifier and power supply system varies in different types of LED bulbs (for home or industrial use), which significantly influences current waveforms.

\section{Measurements and analysis of results}

The quality of electricity drawn by LED lights was analyzed by testing more than ten randomly selected LED bulbs for lighting homes, industrial premises and roads with the use of the HIOKI 3196 power quality analyzer. The analyses involved measurements of current, voltage and power as well as higher current and voltage harmonics at the place of supply. Transient states during connection and disconnection from the power grid were evaluated. The registered higher current harmonics generated to the grid are presented in Figure 1 for home lights, in Figure 2 for industrial lights, and in Figure 3 for road lights. The phase angle between current and voltage for the first harmonic is presented in Figure 4. The current waveform for a household light is presented in Figure 5a, and for a road light - in Figure $5 b$.

\section{Conclusions}

Modern LED lights have high luminous efficacy and long life, as well as the following characteristics:

- LED lights draw deformed current by generating higher current harmonics to the power grid (Fig. 1,2 and 3),

- LED lights decrease the power factor to $\mathrm{PF}=0.53$ for household lights (Fig. 4) and $\mathrm{PF}=0.93$ for road lights, and they draw passive inductive power from the grid, 


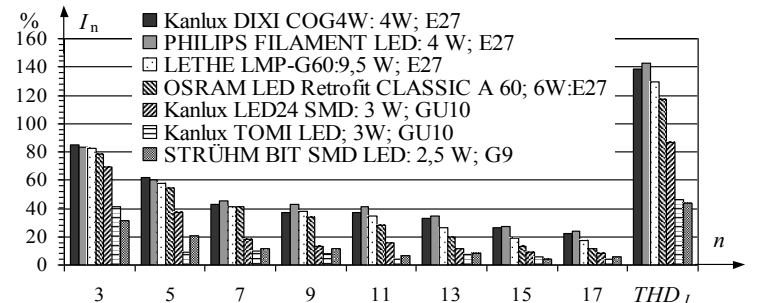

Fig.1. Percentage of higher current harmonics and $T H D_{\mathrm{I}}$ drawn from a low-voltage power grid by household LED bulbs.

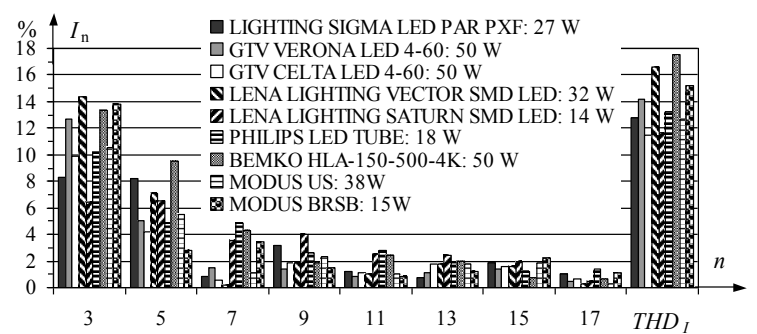

Fig.2. Percentage of higher current harmonics and $T H D_{\mathrm{I}}$ drawn from a low-voltage power grid by industrial LED bulbs.

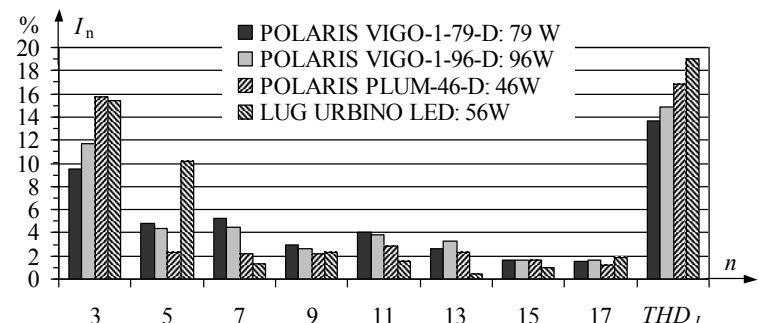

Fig.3. Percentage of higher current harmonics and $T H D_{\mathrm{I}}$ drawn from a low-voltage power grid by road LED lights.

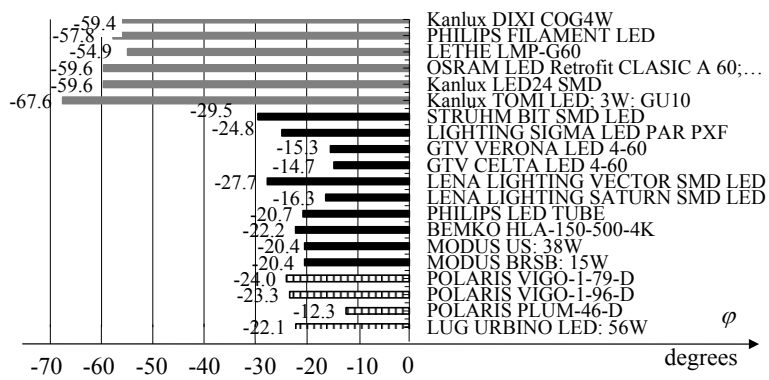

Fig.4. Phase angle between voltage and current for the first harmonic in the tested LED bulbs.

a)
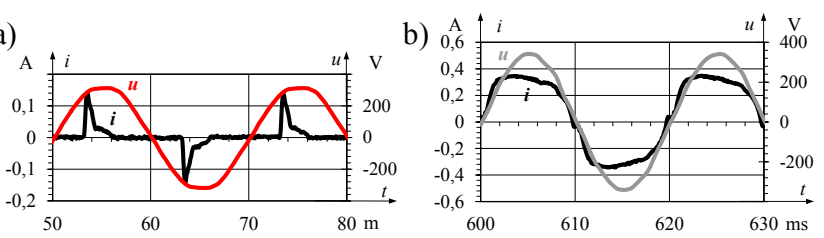

Fig.5. Steady-state current waveform for: a) PHILIPS

FILAMENT LED bulb for household use: 4 W; E27; b)

POLARIS PLUM-46-D road light.

- most household bulbs have a simple rectifier system with a capacitor for smoothing the voltage transmitted to LED diodes (Fig. 5); therefore, they also generate higher values of higher harmonics reaching $T H D_{\mathrm{I}}=140 \%$ (Fig. 1) than industrial and road lights which generate higher harmonics that do not exceed $T H D_{\mathrm{I}}=20 \%$ (Fig. 2 and 3 ),

- lighting fixtures for home use should be equipped with passive [12] or active [13] filters, whereas industrial and road lighting fixtures should be fitted with active filters [13] to minimize their negative effects on the power grid;

- higher harmonics in supply voltage increase with the absorption of higher current harmonics, which can lead to electrical current resonance,

- all of the tested LED lights meet the limits for higher harmonics generated to the power grid, as stipulated by the referenced standards and regulations in [1] to [12],

- industrial and road lights first charge the capacitor, and LED diodes are gently activated after more than ten voltage waveforms.

\section{References}

1. Polish Power Law of 25 September 2012. Journal of Laws, item 1059, volume 1

2. Directive 2014/30/EU of the European Parliament and of the Council of 26 February 2014 on the harmonisation of the laws of the Member States relating to electromagnetic compatibility

3. Regulation of the Minister of the Economy of 4 May 2007 on the detailed operating requirements for the electric power system.

4. EN 50160: 1998. Voltage characteristics of electricity supplied by public distribution systems

5. IEEE Std 1459-2010 Standard Definitions for the Measurement of Electric Power Quantities Under Sinusoidal, Nonsinusoidal, Balanced, or Unbalanced Conditions; IEEE, New York, 2010

6. EN 61000-3-2:2014-10: Electromagnetic compatibility (EMC) - Part 3-2: Limits for harmonic current emissions (equipment input current $\leq 16 \mathrm{~A}$ per phase)

7. EN 61000-3-12:2012: Electromagnetic compatibility (EMC) -Part 3-12: Limits - Limits for harmonic current produced by equipment connected to public low-voltage systems with input current $>16 \mathrm{~A}$ and $\leq 75 \mathrm{~A}$ per phase

8. EN 61000-4-30:2015 Electromagnetic compatibility (EMC) - Part 4-30: Testing and measurement techniques - Power quality measurement methods

9. EN 61000-4-7:2007/A1:2011: Electromagnetic compatibility (EMC) - Part 4-7: Testing and measurement techniques - General guide on harmonics and interharmonics measurements and instrumentation, for power supply systems

10. Commission Regulation (EU) No $1194 / 2012$ of 12 December 2012 implementing Directive 2009/125/EC of the European Parliament and of the Council with regard to ecodesign requirements for directional lamps, light emitting diode lamps

11. Commission Regulation (EC) No 244/2009 of 18 March 2009 implementing Directive 2005/32/EC of the European Parliament and of the Council with regard to ecodesign requirements for non-directional household lamps

12. T. Białoń, M. Pasko, J. Mirowski, M. Kurkowski, Elektryka 238, 49-68 (2016)

13. T. Adrikowski, Elektryka, 228, 77-88 (2013) 